\title{
Delimitation of electrofacies and oil-water contacts in carbonate reservoirs using well logs together with fuzzy logic and neural network
}

\author{
Tamires Soares \& Abel Carrasquilla ,UENF/CCT/LENEP, Macaé - RJ, Brazil
}

Copyright 2018, SBGf - Sociedade Brasileira de Geofísica

Este texto foi preparado para a apresentação no VIII Simpósio Brasileiro de Geofísica Salinópolis, 18 a 20 de setembro de 2018. Seu conteúdo foi revisado pelo Comitê Salinópolis, 18 a 20 de setembro de 2018. Seu conteúdo foi revisado pelo Comitê Técnico do VIII SimBGf, mas não necessariamente representa a opinião da SBGf ou
de seus associados. É proibida a reprodução total ou parcial deste material para propósitos comerciais sem prévia autorização da SBGf.

\begin{abstract}
This study addresses the determination of the electrofacies and the oil-water contact in a carbonate reservoir of Campos Basin, Southeast Brazil. This was done using gamma ray, density, neutron porosity, photoelectric effect, delay time and nuclear magnetic resonance well logs, together with fuzzy logic and neural nets. To validate the results, a comparison was made between real and synthetic density and water saturation curves, in the determination of electrofacies and oil-water contacts, respectively. These oil-water contacts were verified through resistive sections of the resistive log and the diffusion coefficient of the nuclear magnetic resonance log. The results found presented a good correspondence between them, demonstrating that the adopted approach is good.
\end{abstract}

\section{Introduction}

Several reservoir petrophysical parameters can be analyzed using logs, such as lithology, porosity, density, resistivity, oil-water contacts, salinity, etc. Logs have a complex behavior, because they are geometric tools that try to detect irregular structures, which can be considered as multifaceted problem which has intricate relationships among many different variables (Hiran \& Eugenio, 2014. Thus, these various factors affect their registers and limit the applicability of linear mathematical techniques that may facilitate the understanding of this complicated problem. To distinguish these parameters and avoid problems in interpretation, it is therefore necessary to look for nonlinear mathematical methods that are useful in the generation and validation of well as to answer the questions that arise in the characterization of the reservoir (Romero \& Gomez, 2004 ).

\section{Methods and Results}

To identify diverse sedimentary electrofacies, the differences in porosity, density and clay volume within the geological formations were explored. In the delineation of the oil - water contact, water saturation was calculated using Archie model, which porosity was estimated from neutron porosity and nuclear magnetic resonance logs. Also, to evaluate the fluid contact a resistivity section was created from the resistivity logs and a diffusion analysis was done from the nuclear magnetic resonance log. All the results with real data were compared with the synthetic ones, aiming to find the logs that most influence the searched parameters.

\section{Conclusions}

The use of different well logs allowed to separate different electrofacies which may be related to change of depositional environment associated with the formation of a carbonate platform. Water saturation curve, resistivity sections and the diffusion coefficient allowed the marking of the contact between fluids through the inflection in the curves, zones with more of less resistivity due to the presence of oil or water (see Figure 1 and 2) and, when minimum values appeared. To validate all these results, synthetic curves for porosity, resistivity and density logs were created using neural networks and fuzzy logic (Figure 3). The depth values determined by the different approaches shows good agreement.

\section{Acknowledgment}

We thank Petrobras S.A. for the dataset and research project, to $\mathrm{PRH} P B 226$ by the research grant, to LR Senergy for academic license of Interactive Petrophysics software and Petrobras/ANP/UENF for grant and fees.

\section{References}

Al-Bulushi, N.; Araujo, M.; Kraaijveld, M. \& Jing, X. 2007. Predicting water saturation using artificial neural networks. SPWLA Middle East Regional Symposium, Abu Dhabi, UAE, SPWLA-MERS-2007-W.

Hiran, S. \& Eugenio, D. 2014. Alternative methods of identifying the oil water contacts in stratigraphy columns with multiple reservoirs. SPWLA 55th Annual Logging Symposi-um, Abu Dhabi, UAE, SPWLA-2014-UU.

Romero, P. \& Gomez, N. 2004. Method for characterization of rock quality based on Winland Pittman and Timur-Coates equations applied to NMR laboratory data. SPWLA 45th Annual. Logging Symposium, Noordwijk, Netherlands, SPWLA-2004-DDD. 


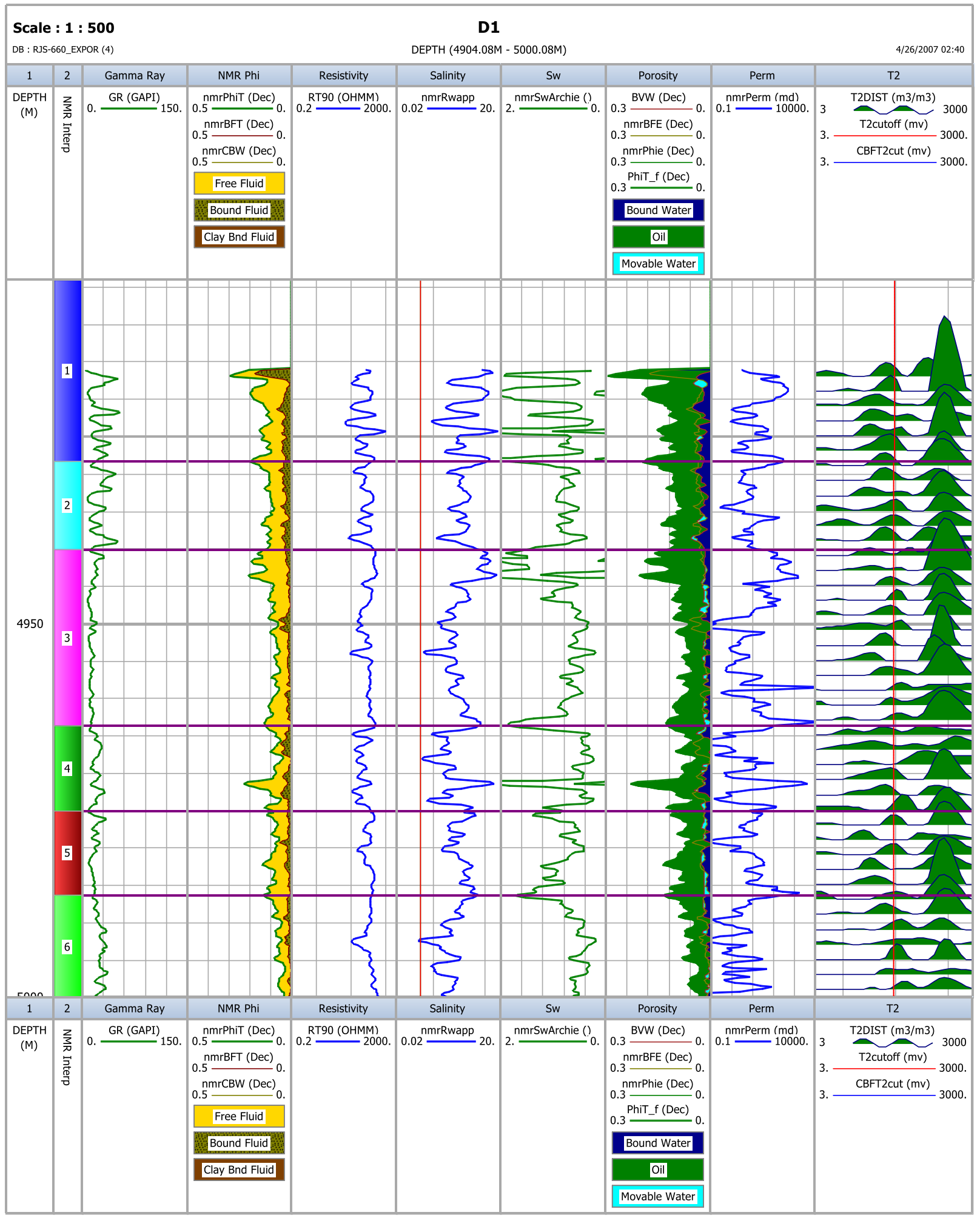

Figure 1: Tracks for well D1: 1) depth; 2) fluid contacts; 3) resistive logs; 4) salinity; 5) saturation; 6) Porosity; 7) Permeability and 8)T2 Distribution; 


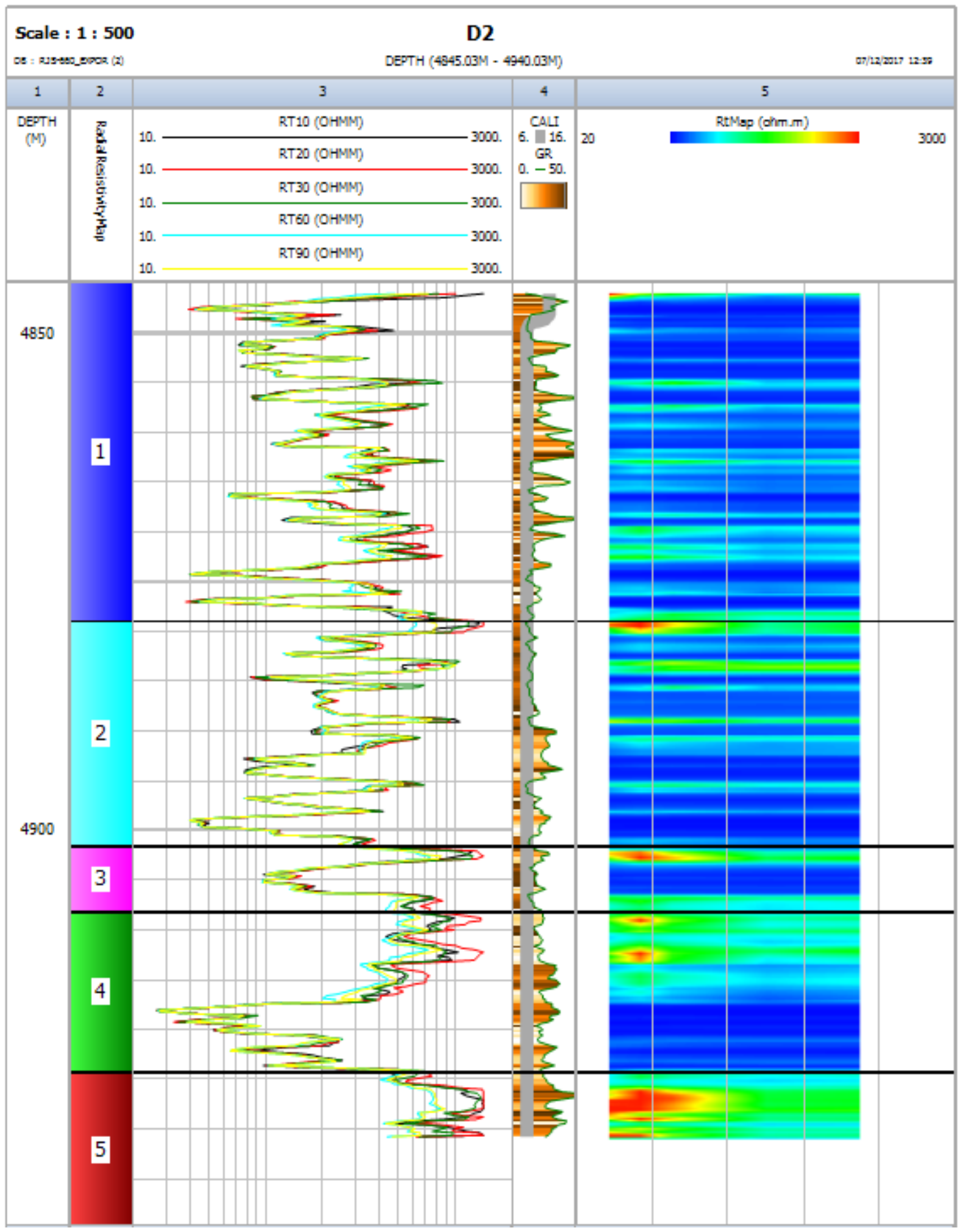

Figure 3. Tracks for well D1: 1) depth; 2) fluid contacts; 3) resistive logs; 4) caliper and gamma ray logs and 5) resistivity images 

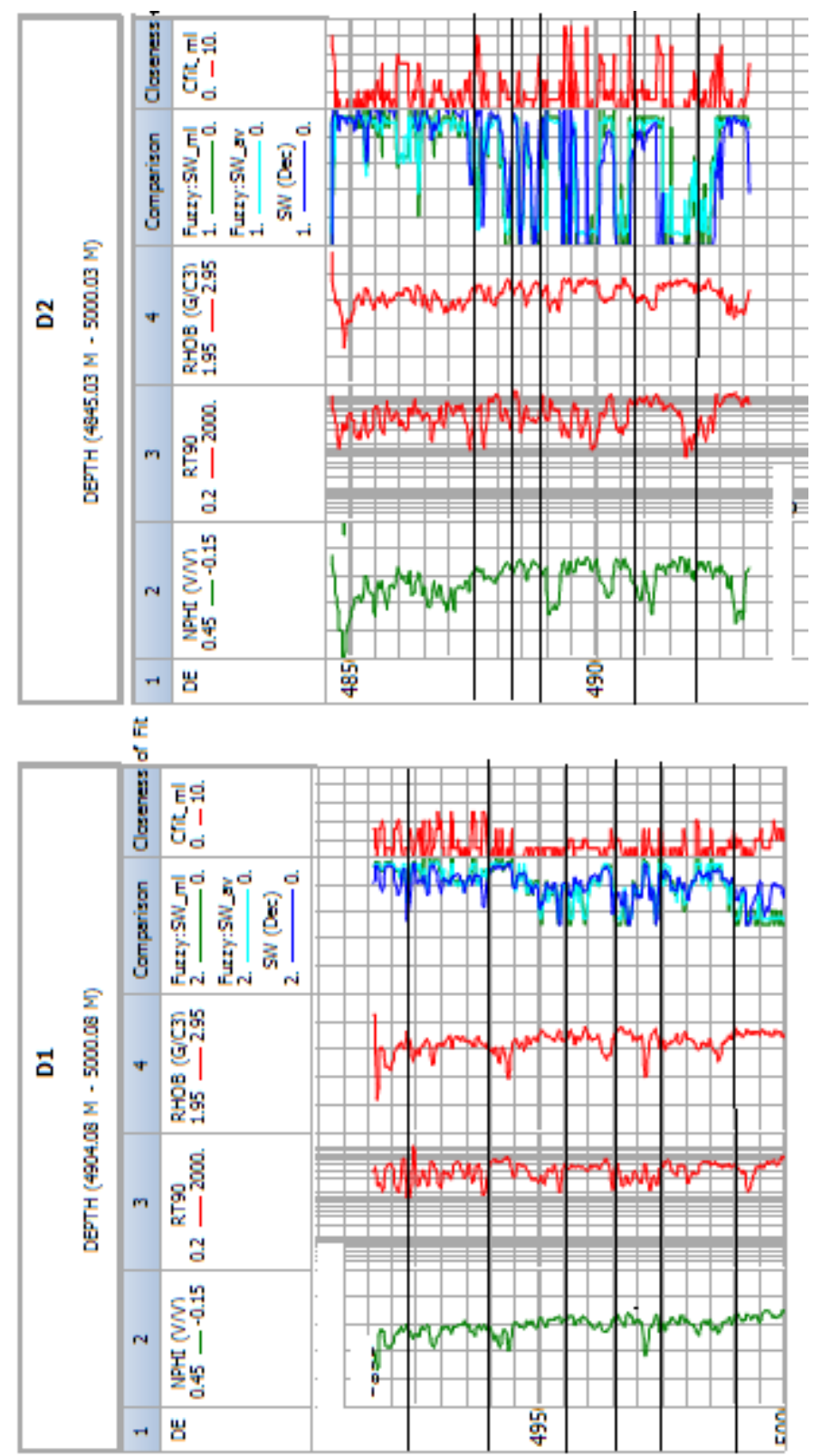

Figure 3: Prediction of water saturation curves using fuzzy logic. The oil-water contacts are zoned in the reservoir 